\title{
Lithofacies Variation and its Consequence on the Reservoir Quality of Kangan Formation in Fars and Persian Gulf Area
}

\author{
Mohammad Hassani-Giv (National Oil Company)
}

\begin{abstract}
Kangan Formation of Lower Triassic is one of the most important hydrocarbon reservoirs in Fars and Persian Gulf areas. The Kangan Formation unconformably is underlain by Permo-Triassic while its upper boundary with Aghar Shale Member of Dashtak Formation is conformable. Containing mainly carbonate rocks, Kangan Formation is interbedded especially in the Upper part with shale and claystone which can be considered as equivalents of Sudair Shale sourced from south west. In some parts of the Fars area, the nearly clean carbonates of the Kangan Formation ranging from tidal flat to shoal in terms of depositional environment, abruptly change to argillaceous limestone and shale of outer ramp (Figure1). In this case, a clay content map provides a powerful mean to delineate the area rich in clay; where is called "Gray zone"(GZ) hereafter. With a length of $350 \mathrm{~km}$., a width of $100 \mathrm{~km}$ and an Azimuth of $150^{\circ}$, the GZ extends from Khalfani field located on the coast of Persian Gulf to Dashtak field in interior Fars area, forming $\sim 30^{\circ}$ angle against main Zagros fault. Such argillaceous facies, named "vermicular limestone", has been reported from Dena and Oshtorankuh both located in high Zagros outcrops. Generation of such a narrow, long trough could be considered as a result of the activation of a number of main faults during the Neothetis opening. In terms of dimensions and the depositional settings, the GZ. likely provided a location for anoxic conditions, hence organic matter enrichment, due to limited oceanic water circulation. Thin section study revealed the presence of such enriched lamina, however, analyzing three geochemical samples from the well SBN ranks them as poor source rocks (TOC: $0.42-0.6$ ).
\end{abstract}

The reservoir units of Kangan Formation usually coincide with the less dolomitized grainy facies deposited in an ooid/bioclastic shaol. Leaching process has yielded mainly moldic, and to some extent, enlarged interparticle porosity. The dolomitic facies deposited in a tidal flat to lagoonal settings. The successive severe precipitation of anhydrite has resulted in occluding pore spaces. Furthermore, the reservoir quality of Kangan Formation in the GZ. decreased due to developing a deep muddy facies. Generally, the Kangan Formation deposited in a regressive cycle. Falling sea level through time caused an interesting basinward migration of grainy facies and porous intervals.

In conclusion, a close interrelationship between the depositional environment, lithofacies and diagenetic processes were observed. 


\section{EAGE}

N. Pars

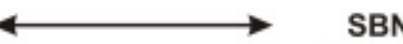

$\longleftrightarrow$ BDT

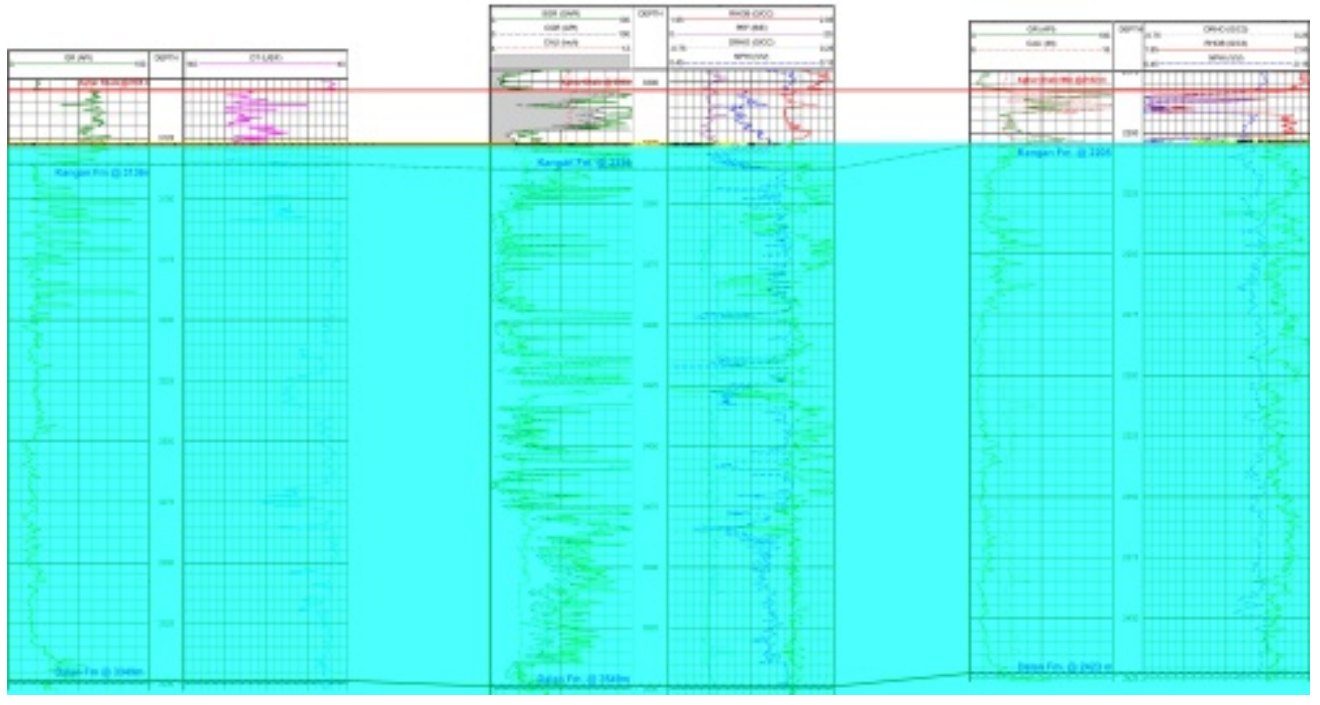

Figure 1: A stratigraphical correlation chart through wells N.Pars, SBN and BDT 